\title{
The Impact of Informal Caregiving on Labour Supply Before and After a Parent's Death
}

\author{
Hanna Vangen ${ }^{1}$
}

Received: 4 September 2019 / Accepted: 30 March 2020/ Published online: 30 April 2020

(C) The Author(s) 2020

\begin{abstract}
Most European countries are facing an ageing population, which points to a need for having as many people as possible of employable age working full time. The growing number of older people increases the pressure on health and care services as well as on family caregivers. Adult children are important care-providers in their parents' final years. This study investigates how having a parent in need of care affects sons' and daughters' labour market participation. The question is investigated by analysing longitudinal data from the Norwegian life course, ageing and generation study. The empirical strategy is first to use register information about parents' demise as an indicator for amplified care needs in the period prior to their death and explore patterns in labour market participation (employment and earnings) before and after the death of a parent. Then, register data are combined with survey data in order to separate caregivers from non-caregivers prior to the loss of a parent. The analyses show a negative employment trend in the years before and after the loss of a lone parent. They also show a different development in earnings between caregivers and non-caregivers. Caregivers have a weaker development in earnings both before and after the death of their parent compared to non-caregivers. The study concludes that caring for older parents has a negative impact on the children's labour market participation in both the period with substantial caregiving needs and the period following the parents' demise.
\end{abstract}

Keywords Family care $\cdot$ Older parents $\cdot$ Employment $\cdot$ Earnings $\cdot$ Gender $\cdot$ Norway

\section{Introduction}

This paper investigates the impact of providing care to older parents on adult children's labour market participation in Norway. With ongoing population ageing, the share of older people in the population increases, and consequently, the number of individuals in

Hanna Vangen

hanna.vangen@oslomet.no

1 NOVA - Norwegian Social research, Oslo Metropolitan University, Stensberggata 26, 0170 Oslo, Norway 
need of health and care services is expected to grow. Simultaneously, more women are participating in the labour market (Colombo et al. 2011). Overall, the increase in the number of older men and women is expected to cause a shortage of family caregivers, as well as health and care personell. Thus, policymakers across Europe have started to stress policies that promote later retirement and encourage family care (Ministry of Health and Care Services 2011; Foster and Walker 2015; Moussa 2019). There is, however, a potential conflict between such policies and experiences of conflicting demands may be a possible outcome at the individual level. Employees with parents in need of care may face increasing pressures for providing care while at the same time being expected to remain in full-time employment until retirement age. Knowledge about how people adapt to such a situation is of importance for policymakers who are aiming at creating a sustainable welfare state and preventing inequality (Ulmanen and Szebehely 2015; Gautun and Bratt 2016; Birtha and Holm 2017; COFACE 2015).

Previous research has documented a negative relationship between caregiving demands and labour supply (Bauer and Sousa-Poza 2015; Moussa 2019; Gautun and Bratt 2016). However, this association varies between men and women and across national contexts. The effects of caregiving are found to be larger for women than for men (Bauer and SousaPoza 2015), and weaker in the Nordic countries (Kotsadam 2011). In the Nordic countries, long-term care is a public responsibility and both men and women have a high participation in the labour market compared to countries further south in Europe. A negative impact of caregiving on labour market participation may threaten the sustainability of the welfare system if such societies move towards relying more heavily on family care (Verbakel 2017).

The primary objective of this paper is to increase knowledge regarding how caregiving to old parents in need of care affects adult children's labour market outcomes (employment and earnings). The question is investigated by analysing longitudinal data from the Norwegian study of life course, ageing and generation (NorLAG). NorLAG offers individual survey data on provision of help and care to parents combined with annual register data on employment and earnings for the years prior to and after the loss of parents. Thus, the data provides the possibility to investigate how actual care provision to parents is related to labour market participation over a period of up to 30 years of adult sons' and daughters' life.

\section{Family Care and Labour Market Participation}

Until the 1990s, research on issues regarding the combination of work and family care traditionally focused more on combining paid work and care for young children (Leira 1996) than on combining employment and care for older family members (Kotsadam 2011). When scholars started to address how adult children's care obligations to elderly parents affected their labour market participation, most research was undertaken in the US and UK (Gautun and Bratt 2016). In recent years, studies have been extended to many other countries (Bauer and Sousa-Poza 2015; Kotsadam 2011; Kröger and Yeandle 2013; Moussa 2019), including Norway (Gautun and Hagen 2010; Daatland et al. 2010; Gautun and Bratt 2016; Ugreninov 2013; Jakobsson et al. 2013; Fevang et al. 2012; Kotsadam 2012; Abrahamsen and Grøtting 2019; Løken et al. 2017).

Research shows that caregiving has consequences for labour supply at both the extensive and the intensive margin. Caring for older parents might have a negative 
effect on employment probability (Fevang et al. 2012; Crespo and Mira 2014), but employment can also prevent adult children from engaging in caregiving (Carmichael et al. 2010). For those in employment, one strategy for coping with caregiving is to reduce work hours (Gautun and Hagen 2010). In line with this finding, earnings have been found to be lower among caregivers than among non-caregivers (Van Houtven et al. 2013; Heitmueller and Inglis 2007), and there is also evidence of a wage penalty for caregivers in the long run (Schmitz and Westphal 2017).

Although a large share of studies show negative effects of caregiving on labour supply, a recent review article shows that the results are dependent on how employment and caregiving are measured, methods used and the selection of study sample (Moussa 2019). Care intensity is often measured by the number of hours used to provide care or how often care is provided (i.e. the number of times per month or week). Non-temporal measures are also used to determine the degree of care intensity; Care that is given to persons living in the same household is considered to be more intensive than extraresidential care, personal care is regarded as more intensive than help with practical chores, and being the primary caregiver is more intensive than being a secondary caregiver (Moussa 2019). Also, in a Canadian study, end-of-life care was found to be a good proxy for measuring intensive care compared to short-term and long-term care (Williams et al. 2014). Several studies show that the effect of caregiving on employment pertains only to the most intensive caregivers, while less intensive care is more likely to result in reduced working hours than exit from work (Moussa 2019; Jacobs et al. 2017; Lilly et al. 2007; Kotsadam 2012).

Several studies investigating the association between informal caregiving and labour market outcomes have raised the problem of reverse causation (Heitmueller 2007; Kotsadam 2011, 2012; Carmichael and Charles 2003; Bolin et al. 2008; Moussa 2019). The challenge is to disentangle the proposed causal effect of providing care on labour market participation from selection into caregiving. Caregivers may be self-selected underemployed individuals who have lower costs related to caregiving, or they may be men and women with more capability for combining caregiving and labour market participation. In order to identify the causal relationship between caregiving and work, adult children who already have a lower labour market participation before starting to provide care must be separated from those who reduce their work hours because of caregiving responsibilities.

In general, daughters are more often caregivers than sons (e.g. Kotsadam 2011; Bauer and Sousa-Poza 2015; Grigoryeva 2017). An explanation from the neo-classical tradition is that women have weaker attachment to the labour market than men and thus lower opportunity costs associated with caregiving (Carmichael and Charles 2003). The economic cost of caregiving is assumed to be lower for low-skilled, low-paid, part-time workers and those already unemployed (Colombo et al. 2011; Ulmanen and Szebehely 2015), and women are more often represented in these groups. Previous studies also show that daughters are more exposed to negative labour market outcomes due to caregiving compared to sons, mainly explained by the more intensive care provided by daughters (Bauer and Sousa-Poza 2015).

The present study is inspired by a Norwegian study based on registry data conducted by Fevang et al. (2012). The authors used the demise of a lone parent as a proxy for higher caregiving needs in the period prior to the death of the parent and found a drop in employment, a small but significant negative effect on earnings, and a rising risk of claiming social benefits around a parent's death year/month. Also a recent Swedish 
study based on registry data, found a correlation between the loss of a parent and work exit (Kridahl and Silverstein 2019). In both studies, it was assumed that the reported employment effects were caused by caregiving in the terminal stage of a parent's life. However, registry data do not provide information on actual care provision. The novelty of the present study is to use register data linked to survey data to broaden the understanding of register-based results in the mentioned studies.

\section{The Case of Norway in a Comparative Perspective}

Previous research shows that evidence regarding how individuals behave in the work and care nexus cannot be automatically transferred across welfare contexts. Negative employment effects for caregivers depend on the level of formal care that is available in different welfare states (Kotsadam 2011; Spiess and Schneider 2003). Norway, like the other Nordic countries, is characterised by extensive welfare services and a public responsibility for longterm care, combined with no legal obligations for adult children to care for older parents. The high degree of what Saraceno and Keck (2010) called de-familialisation in Norwegian social policy has resulted in high rates of female labour market participation. However, even in Norway, informal care makes up a significant share of the total care available to the adult population. Estimations have shown that the share of informal care is approximately $40 \%$ of all care provision (Holmøy et al. 2016). A number of studies have shown that the generous public care services available in the Nordic countries are associated with more family caregivers but less intensive help and care. In countries with lower levels of public care services, the overall number of family caregivers is lower, but more of the caregivers provide frequent personal care (Verbakel 2017; Brandt 2013; Brandt et al. 2009; Strauss and Trommer 2018). Because of the high level of public care services in the Nordic countries and because of family caregiving being a choice rather than a legal obligation, it has been suggested that the effects of caregiving on labour market participation are weaker compared to countries representing more family-oriented welfare models (Kotsadam 2011; Spiess and Schneider 2003). Recently, it has been suggested that family care has become less optional in Norway, as well as in the other Nordic countries, because of declining public care services (Jolanki et al. 2013; Gautun and Bratt 2016; Ulmanen and Szebehely 2015; Van Den Broek et al. 2019). This calls for updated research on how labour market participation and individual earnings of adult sons and daughters are affected by caregiving responsibilities in the Nordic context.

\section{Data and Method}

In order to investigate the consequences of care provision to older parents on adult children's labour market participation, the effect of caring for older parents in the terminal phase is investigated by analysing longitudinal survey and registry data from the Norwegian life course, ageing and generation study (NorLAG). ${ }^{1}$ More specifically,

\footnotetext{
${ }^{1}$ NorLAG2 (2007/2008) was the second wave of NorLAG and include a total of 15,145 respondents from the whole country in the age group 18-79. Data collection for the third wave (2017) includes 6099 participants aged 50 years and older who responded to at least one of the previous two waves, of which 5711 responded both in 2007/8 and 2017 (Torsteinsen and Holmøy 2019).
} 
the sample consists of individuals participating in wave 2 (2007/2008) of NorLAG who lost a lone parent during the five-year period after the survey (248 daughters and 265 sons aged 40 to 66 ). ${ }^{2}$ The survey data was collected by computer-assisted telephone interviews (CATI) carried out by Statistics Norway in 2007/2008. The survey data was then linked to 50 years of register data between 1967 and 2017. The register data includes information on earnings, social security benefits and pensions, ${ }^{3}$ in addition to family members.

Compared to the large sample used in Fevang et al. (2012), with register observations from 308,706 Norwegian individuals in the years 1993 to 2005, the sample used here is considerably smaller. However, this study contributes with the use of linked data - a combination of survey and registry data. The survey data are used to identify actual caregivers, whereas information on earnings and parents' death year come from registry data. The linked design allows for the creation of groups of caregivers and noncaregivers based on information from the survey and for these to be followed several years before and after the survey, using updates from the registers.

\section{Caregiving in the Terminal Phase of a Lone Parent's Life and Labour Market Participation}

The strategy in this paper is to explore whether self-reported caregivers deviate from non-caregivers in the time path of the dependent outcome variables (employment and earnings) before and after the death of a lone parent. Annual records of pensionable earnings are collected by the Norwegian tax and income registers. Employment is measured as having annual earnings exceeding the basic amount $(\mathrm{G})$ in the national insurance scheme, represented by a dummy variable where 1 is employed and 0 not employed. The annual earnings are standardised by dividing them by the amount representing one $\mathrm{G}$ for each observation year. ${ }^{4}$

Caregiving is operationalised as time to death, interacted with a direct observation of caregiving from the survey. First, the parent's death year is used as a proxy for amplified care needs as the parent is approaching death. The year of a parent's death is collected from register data, supplemented by information from the 2017 survey wave in case of missing information from the register. ${ }^{5}$ All observations are given a value representing how far in time the observation is from the parent's death. Because of a limited number of observations, the variable is collapsed to represent two and two years in the period before and after the parent dies. The reference level is eight or more (up to 20) years before the death year of a parent and the last observation is up to 10 years after.

In NorLAG2 (2007/2008), the respondents were asked in a telephone interview if they had regularly (at least monthly) given practical help to someone outside the household during the last 12 months. If they answered yes, they were then asked to

\footnotetext{
2 Three respondents lost two parents that both were unmarried or divorced in the five-year period following the survey. Therefore, the sample was restructured to consist of parent-child dyads.

${ }^{3}$ Data on social security benefits and pensions are only available between 2002 and 2017.

${ }^{4}$ Currently (2019/2020), the basic amount (G) is 99,858 NOK.

${ }^{5}$ Reasons for missing data on parents' death year: in some situations it is difficult to identify the parents of an individual in the registers. One reason can be that the parents have lived abroad. There is also less information available in the registers about kin for individuals born before the year 1952.
} 
whom they had provided help (by naming up to five persons using a list of alternatives, including mother and father). The same question was repeated for personal caregiving (e.g. eating, getting up in the morning, getting dressed, bathing or using the toilet). Information about both regular help and personal care are combined into a dummy variable indicating caregiving. The value 1 represents caregivers (providing regularly help or personal care) and 0 represents non-caregivers. In the analyses, this dummy variable is interacted with the variable indicating the time to the parent's death.

The approach using the death year of a parent as a proxy for care needs relies on literature that states that need for care is higher in the final years of life (Romøren 2003; Gabrielsen 2013; Williams et al. 2014). Towards the end of life, it is also more common to make use of formal long-term care services. According to Gabrielsen (2013), $80 \%$ of the 80 to 85 year olds who died in 2011 in Norway had been users of public services. Among those above 90 years, the same was the case for close to $100 \%$. Of these, $62 \%$ had been in long-term residence in a nursing home, and the median length of stay in long-term institutions before death was 1.3 years $^{6}$ (Gabrielsen 2013). Romøren (2003) showed that the period with support from family informal caregivers before institutionalisation and/or death lasted for on average of 5.4 years, and was dominated by practical help. For about one-third of the caregivers, this "main phase" of caregiving was followed by an "escalation phase" of an average of 22 weeks before institutionalisation in a nursing home or hospital characterised by intensive personal care (Romøren 2003, pp. 98-100).

The use of a single measurement of caregiving from the survey $0-5$ years before the parent's death year may be criticised for overlooking the fact that respondents who did not report giving care to older parents in the survey started to provide help or care between the survey and their parent's demise. Some may also have stopped or reduced their caregiving because the parent moved into an institution (nursing home). Although the estimates would probably have been more accurate with annual data on caregiving, it can be argued that a significant result in this study may indicate an identification of a "lower bound". Also, the definition of care, consisting of both regularly provided practical help and personal care, can be criticised for being too wide. However, this broad definition indicates a relationship in which adult children support their parents. The assumption that these adult children are more likely to continue or reinforce their support when their parent's needs increase than those who did not report any support at all in the survey is supported by previous literature (Leopold et al. 2014). Finch and Mason (1993) used the concept of developing commitments to show that the selection of caregivers develops through more or less silent negotiations within families over time, often starting long before the actual care takes place. Support to parents in terms of help or care is therefore not only an expression of behaviour at the specific time of the survey but can be used as a token for a long-lasting close relationship in which caregiving plays a natural part.

It is a potential source of bias that individuals are studied in a limited observation window. The timing of a parent's death in this window is not independent of the timing of a parent's death in the individual's life course (Fevang et al. 2012, p. 1409). The timing of a parent's death in the life course may also be correlated with the individual's

\footnotetext{
${ }^{6}$ The average was two years, but while some stays last much longer than others, the median is a more accurate measure of the general length of these stays. Three out of four stays lasted less than three years.
} 
health and social background and bias the estimates if the observation window systematically limits the representation of individuals. Respondents who lost their parent in later years do contribute with more observations before the death of a parent and fewer observations after. Hence, those who lose their parents earlier contribute with more observations after the death year than those who lose their parents later, and if these people are systematically different from each other, it could be a source of bias. This problem is handled using fixed effects. In the fixed-effects model, a timedemeaning procedure is used to subtract the value of every observation on the dependent and independent variables from the person's mean. In other words, individuals are compared with themselves over time. All variables that are constant over time, both observed and unobserved, are cancelled out by this procedure and only timevariant variables that may be correlated with both parental death and the labour market outcomes need to be controlled for.

The fixed-effects model is executed by the xtreg, fe-command in the software package Stata/MP 14.2. In general, logit regression is viewed as more suitable than linear regression for binary dependent variables such as employment, because they guarantee that the probability of $y=1$ is between 0 and 1 . However, when using a logit model with fixed effects on panel data, individuals who do not vary on the dependent variable throughout the whole period are excluded from the analyses and the sample size is drastically reduced. Additionally, the linear probability model provides results that are easier to interpret. Therefore, the last model is preferred in this study, but the analysis of employment is also conducted using the conditional logit model and available in Appendix (Table 4).

The relationship between time to a parent's death year and an individual's participation in the workforce could be related to processes that change over time at both individual and societal level. Such processes could be individual ageing or policy reforms such as the Norwegian pension reform of 2011. All studies that have an interest in concepts that change over time encounter the challenge of disentangling age, period and cohort effects, also called the age-period-cohort (APC) conundrum (Glenn 2005). The problem is collinearity between age, time and cohort and not being able to include two of the dimensions in a regression model and let the third vary freely because Age $=$ Year - Birth year. In this study, the dependent variable, time to a parent's death year, is a fourth dimension related to time and collinear with both age and observation year. A suggested solution to the APC problem is to recode the variables so that they are no longer perfectly collinear - for instance, by grouping years or ages together (Mason et al. 1973). In the present paper, the scale of the independent variable, time to death, is collapsed into two or more years together, which makes it technically possible to control for other APC dimensions in the model. In models with individual fixed effects, the birth cohort is treated as a constant variable that is already "controlled for" and therefore automatically omitted from the model. This means that only one of the other APC dimensions can be included without having to adjust the variables to break the collinearity. To be technically able to control for both age and calendar year in the same model, the age levels 49 and 50 years are collapsed together. This restriction builds on an observation in the data that there is a period around the age of 50 where earnings do not seem to change and where employment rates are more or less constant (as shown in Biørn et al. 2013).

As previously mentioned, studies that aim to explore whether there is an effect of caregiving on labour supply face a problem with reversed causation. Fevang et al. 
(2012) use the event of a parent's death as an exogenous instrument to estimate causal effects of caregiving demands on labour supply in the years around this event. Still, they cannot rule out other explanations of the change in employment and earnings. This study shows how a group of self-reported caregivers deviate from non-caregivers in their labour supply around the same event, by including an interaction term representing caregivers. However, the allocation into the caregiver group is not exogenous with reference to labour market participation. The individual fixed effects only control for heterogeneity between individuals, and not endogenous change within the individual time paths. Labour market participation ahead of the decision to provide care can therefore be a source of endogeneity in how the two groups differ in their trends. Nevertheless, the aim of this study is not primarily to detect an effect with a statistical model that satisfies the assumptions needed to make causal inference within a counterfactual paradigm. The paper contributes to the literature by complementing the conclusions drawn by Fevang et al. (2012) with descriptive evidence regarding how the two groups deviate from each other.

\section{Results}

\section{Descriptive Statistics}

Table 1 summarizes the sample statistics using information from the 2007 survey in the NorLAG study. The two groups of caregivers and non-caregivers are compared both in the total sample and separately by gender. In the regression models presented in the next sections, individual fixed effects - that is, all constant characteristics - are controlled for and, as a result, the variables that do not vary over time are omitted from the models.

Table 1 shows descriptive statistics for caregivers and non-caregivers, both in 2007 , to parents who died in one of the five consecutive years after the survey (2007-2011). In the total sample, 28\% were caregivers, and of these, daughters comprised $61 \%$. Descriptive statistics for caregivers and non-caregivers among sons and daughters are also presented separately. The number and percentage share of sons and daughters being caregivers are reported at the bottom of Table 1 .

There was no significant difference in the average age of caregivers and noncaregivers in 2007. The educational differences between caregivers and noncaregivers were small, and only significant among sons. Caregiving sons were more often higher educated than non-caregiving sons, and the share of "low educated" was higher among non-caregiving sons than among the caregivers. A lower share of caregivers worked full-time (64\%) compared to non-caregivers (73\%), reflecting the gender composition of the two groups; Independent of caregiver status, a smaller share of women worked full-time compared with men in both groups. Among daughters, the share with excellent health was higher among non-caregivers (25\%) compared to caregivers $(13 \%)$, but on the other hand more of the caregiving daughters reported having "good health" $(84 \%)$ than non-caregiving daughters $(67 \%)$. Overall, the table indicates that non-caregiving daughters had somewhat better health, although the share 
Table 1 Descriptive statistics of caregivers versus non-caregivers in 2007. Comparison of mean characteristics in the total sample and for sons and daughters separately

\begin{tabular}{|c|c|c|c|c|c|c|c|c|c|}
\hline & \multicolumn{2}{|l|}{ All } & \multirow[t]{2}{*}{ Sig. } & \multicolumn{2}{|l|}{ Sons } & \multirow[t]{2}{*}{ Sig. } & \multicolumn{2}{|l|}{ Daughters } & \multirow[t]{2}{*}{ Sig. } \\
\hline & Caregiver & $\begin{array}{l}\text { Non- } \\
\text { caregiver }\end{array}$ & & Caregiver & $\begin{array}{l}\text { Non- } \\
\text { caregiver }\end{array}$ & & Caregiver & $\begin{array}{l}\text { Non- } \\
\text { caregiver }\end{array}$ & \\
\hline Daughters & $61 \%$ & $43 \%$ & $* *$ & & & & & & \\
\hline Age & 52.8 & 52.8 & & 53.0 & 52,8 & & 52.7 & 52.9 & \\
\hline Education: Low & $13 \%$ & $15 \%$ & & $9 \%$ & $18 \%$ & + & $16 \%$ & $11 \%$ & \\
\hline $\begin{array}{l}\text { Education: } \\
\text { Middle }\end{array}$ & $41 \%$ & $47 \%$ & & $43 \%$ & $52 \%$ & & $40 \%$ & $41 \%$ & \\
\hline Education: High & $46 \%$ & $38 \%$ & & $48 \%$ & $30 \%$ & $*$ & $44 \%$ & $48 \%$ & \\
\hline Working full-time & $64 \%$ & $73 \%$ & $*$ & $88 \%$ & $87 \%$ & & $49 \%$ & $54 \%$ & \\
\hline Partner & $75 \%$ & $76 \%$ & & $82 \%$ & $79 \%$ & & $71 \%$ & $71 \%$ & \\
\hline $\begin{array}{l}\text { Children in } \\
\text { household }\end{array}$ & $45 \%$ & $45 \%$ & & $48 \%$ & $48 \%$ & & $43 \%$ & $42 \%$ & \\
\hline $\begin{array}{l}\text { Siblings } \\
\text { (mean no.) }\end{array}$ & 1.93 & 2.13 & & 1.96 & 2.17 & & 1.91 & 2.09 & \\
\hline \multicolumn{10}{|l|}{ Self-rated health } \\
\hline Excellent & $20 \%$ & $26 \%$ & & $30 \%$ & $26 \%$ & & $13 \%$ & $27 \%$ & $*$ \\
\hline Good & $77 \%$ & $68 \%$ & $*$ & $66 \%$ & $69 \%$ & & $84 \%$ & $67 \%$ & $* *$ \\
\hline Poor & $3 \%$ & $5 \%$ & & $4 \%$ & $5 \%$ & & $2 \%$ & $6 \%$ & \\
\hline $\begin{array}{l}\text { Standardized } \\
\text { earnings } \\
\text { (Earnings in } \\
\text { NOK/G) }\end{array}$ & 5.4433 & 5.8487 & & 7.3721 & 6.9107 & & 4.2514 & 4.4662 & \\
\hline $\begin{array}{l}\text { Respondents } \\
\text { (N) (per cent) }\end{array}$ & $\begin{array}{l}145 \\
(28 \%)\end{array}$ & $\begin{array}{l}368 \\
\quad(72 \%)\end{array}$ & & $56(21 \%)$ & $\begin{array}{l}209 \\
\quad(79 \%)\end{array}$ & & $89(36 \%)$ & $\begin{array}{l}159 \\
(64 \%)\end{array}$ & \\
\hline
\end{tabular}

$* * p<0.01 * p<0.05+p<0.10$

Two-tailed t-test used in the bivariate analyses.

Source: the Norwegian life course, ageing and generation study (NorLAG), 2007

reporting very poor health was slightly, but not significantly, higher among non-caregiving daughters. Although not significant, earnings in 2007 were lower for caregivers than for non-caregivers both in the total sample and among daughters. For sons, there was an opposite tendency, with higher average earnings among caregiving sons than among non-caregiving sons.

The following analyses take advantage of the linked design of the study and investigate whether the impact of time to loss of parent on the development in employment and earnings is different for caregivers compared to non-caregivers.

Figures 1 and 2 illustrate how the sample of caregivers and non-caregivers (both groups having lost a parent in the period) deviate from the population on the two dependent variables - employment and earnings. Each observation is compared to the mean level in the population within the same gender, age and observation year. The population is represented by the 6099 respondents attending the NorLAG study in the last wave in 2017. 


\section{Employment}
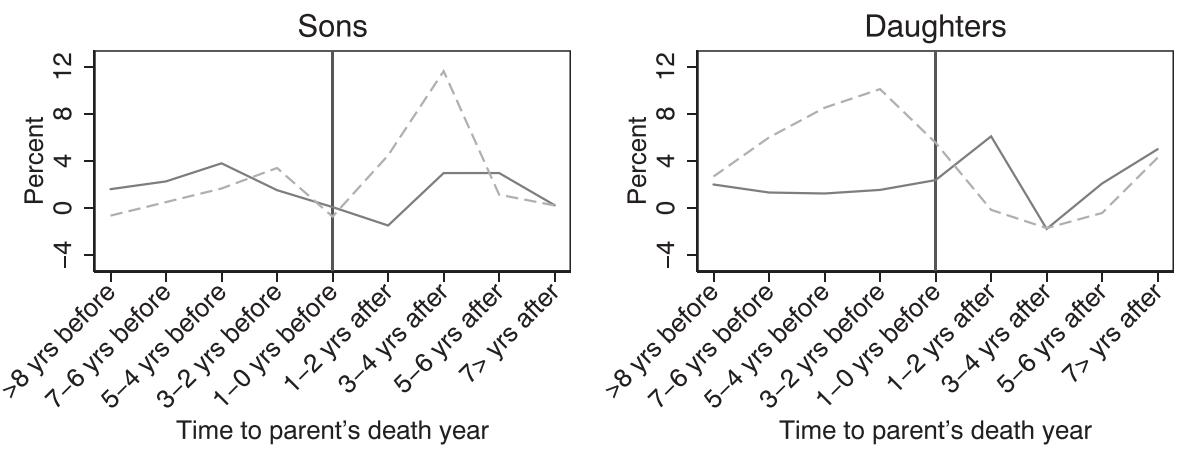

- Non-caregivers ----- Caregivers

Fig. 1 Percentage difference in employment between the sample (caregivers and non-caregivers with a lone parent that died between 2007 and 2011) and the population in the years before and after the death year of a parent, for sons and daughters separately

According to Fig. 1, caregiving sons seem to have a higher employment rate than the rest of the population 3-4 years after a parent's death. Caregiving daughters are on average more likely to be employed than their peers are in the period before a parent's death. The difference in employment between non-caregiving sons and daughters and the rest of the population is most of the time slightly above the population mean. Five and more years after the parent's death, the employment level converges to the population mean for both groups of sons and rises for both groups of daughters who lose their parent.

Figure 2 shows that the level of earnings is higher among caregivers of both genders before the death of a parent, and seemingly more for caregiving sons, compared to both the population and to non-caregivers in the sample. There are lower levels of earnings after a parent's death for both sons and daughters who lose a parent compared to their

\section{Earnings}
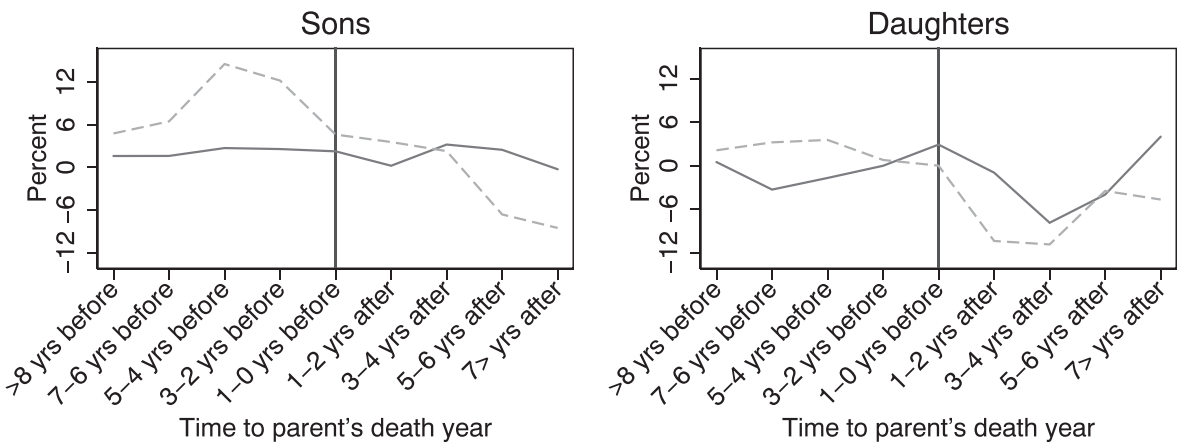

Non-caregivers

Caregivers

Fig. 2 Percentage difference in earnings between the sample (caregivers and non-caregivers with a lone parent that died between 2007 and 2011) and the population, in the years before and after the death year of a parent for sons and daughters separately 
equals in the population in these years. For sons who did not provide care, earnings are relatively stable at the population level in all the years around their parent's death. For daughters, relative earnings are lower for caregivers 1-4 years after the parent's death, but regardless of caregiver status the negative trend is followed by all daughters who have lost a parent 3-4 years after the parent's death.

\section{Impact of Caregiving on Employment}

Table 2 shows results from a linear probability model of employment with fixed effects, controlled for age and calendar year using dummy variables (not shown).

The results show that the probability of being employed is lower in the period around a lone parent's death, for both sons and daughters. Model a shows that the probability of being employed is $6.6 \%$ points lower for sons in the year when a lone parent dies and the year before, compared to a reference period of eight or more years before the parent's death. Employment among daughters is also negatively affected by

Table 2 Results from linear probability regression model of the impact of time (years) to a lone parent's death on employment, controlled for age, calendar year and individual fixed effects. Separate models by gender

\begin{tabular}{|c|c|c|c|c|c|c|c|c|}
\hline & \multicolumn{2}{|l|}{ a. Sons } & \multicolumn{2}{|c|}{ b. Daughters } & \multicolumn{2}{|l|}{ c. Sons } & \multicolumn{2}{|c|}{ d. Daughters } \\
\hline & Coeff. & SE & Coeff & SE & Coeff & SE & Coeff & SE \\
\hline \multicolumn{9}{|c|}{ Time: 8 or more yrs. before (ref.) } \\
\hline 6-7 yrs. before & -0.009 & $(0.015)$ & 0.002 & $(0.019)$ & -0.014 & $(0.016)$ & -0.010 & $(0.021)$ \\
\hline 5-4 yrs. before & -0.012 & $(0.020)$ & -0.004 & $(0.026)$ & -0.019 & $(0.021)$ & -0.010 & $(0.027)$ \\
\hline $3-2$ yrs. before & -0.035 & $(0.026)$ & -0.036 & $(0.033)$ & $-0.048+$ & $(0.026)$ & -0.050 & $(0.034)$ \\
\hline $1-0$ yrs. before & $-0.066^{*}$ & $(0.031)$ & -0.063 & $(0.039)$ & $-0.077^{*}$ & $(0.031)$ & $-0.075+$ & $(0.040)$ \\
\hline $1-2$ yrs. after & -0.047 & $(0.035)$ & $-0.104^{*}$ & $(0.045)$ & $-0.068+$ & $(0.036)$ & $-0.099 *$ & $(0.046)$ \\
\hline 3-4 yrs. after & -0.008 & $(0.040)$ & $-0.135^{* *}$ & $(0.052)$ & -0.032 & $(0.041)$ & $-0.143 * *$ & $(0.053)$ \\
\hline $5-6$ yrs. after & -0.004 & $(0.045)$ & $-0.114 *$ & $(0.058)$ & -0.008 & $(0.045)$ & $-0.116^{*}$ & $(0.059)$ \\
\hline 7-10 yrs. after & 0.010 & $(0.051)$ & -0.089 & $(0.065)$ & 0.000 & $(0.051)$ & -0.090 & $(0.066)$ \\
\hline \multicolumn{9}{|c|}{ Interaction (Time*care): } \\
\hline \multicolumn{3}{|c|}{ 6-7 yrs. before*care } & & & 0.023 & $(0.023)$ & 0.034 & $(0.025)$ \\
\hline \multicolumn{3}{|c|}{$5-4$ yrs. before*care } & & & 0.030 & $(0.023)$ & 0.020 & $(0.025)$ \\
\hline \multicolumn{3}{|c|}{ 3-2 yrs. before*care } & & & $0.050^{*}$ & $(0.023)$ & $0.045+$ & $(0.025)$ \\
\hline \multicolumn{3}{|c|}{$1-0$ yrs. before*care } & & & 0.035 & $(0.023)$ & 0.040 & $(0.026)$ \\
\hline \multicolumn{3}{|c|}{$1-2$ yrs. after*are } & & & $0.075^{* *}$ & $(0.024)$ & -0.007 & $(0.026)$ \\
\hline \multicolumn{3}{|l|}{ 3-4 yrs. after*care } & & & $0.081 * *$ & $(0.025)$ & 0.033 & $(0.027)$ \\
\hline \multicolumn{3}{|c|}{ 5-6 yrs. after*care } & & & -0.024 & $(0.026)$ & 0.016 & $(0.028)$ \\
\hline \multicolumn{3}{|c|}{$7-10$ yrs. after*are } & & & 0.007 & $(0.027)$ & 0.015 & $(0.030)$ \\
\hline Constant & $0.988 * *$ & $(0.298)$ & $0.847 *$ & $(0.384)$ & $0.992 * *$ & $(0.298)$ & $0.850^{*}$ & $(0.384)$ \\
\hline Person-years (n) & \multicolumn{2}{|l|}{7223} & \multicolumn{2}{|l|}{6880} & \multicolumn{2}{|l|}{7223} & \multicolumn{2}{|l|}{6880} \\
\hline Persons $(\mathrm{N})$ & \multicolumn{2}{|l|}{264} & \multicolumn{2}{|l|}{248} & \multicolumn{2}{|l|}{264} & \multicolumn{2}{|l|}{248} \\
\hline $\mathrm{R}^{2}$ (within): & \multicolumn{2}{|l|}{0.123} & \multicolumn{2}{|l|}{0.071} & \multicolumn{2}{|l|}{0.126} & \multicolumn{2}{|l|}{0.072} \\
\hline
\end{tabular}

$* * \mathrm{p}<0.01 * \mathrm{p}<0.05+\mathrm{p}<0.10$ 
the death of a lone parent, but mainly so, and only significant in the years after the parent's death.

The coefficients of the first eight dummy variables in model $\mathrm{c}$ and $\mathrm{d}$ represent how the employment probability develops in the years after the reference period for those who did not report caregiving in 2007. The next eight coefficients, representing the interaction between the time dummies and caregiver status in 2007, show how much the caregivers deviate from this trend. Models $\mathrm{c}$ and $\mathrm{d}$ show no sign of an additional negative effect of being a caregiver on employment. On the opposite, sons who provided care to their parent had a higher probability of being employed both during 2-3 years prior to and 1-4 years after the parent's death.

Figure 3 shows the predicted impact of time to loss of a parent on employment, estimated from the linear probability model with fixed effects and controlled for age and observation year. Overall, the results indicate a negative development in employment around a parent's death, but it cannot be concluded that the decline in employment is related to caregiving from these results.

\section{Impact of Caregiving on Earnings}

Table 3 shows results from a linear regression of the impact of time to death of a parent on the log of standardised annual earnings, conditional on employment in the year of observation.

Model a in Table 3 shows no significant change in earnings in the years around a parent's death for the sons, controlled for age and observation year. The daughters' earnings are decreasing in the same period compared to the reference period of eight or more years before the loss of a lone parent (model b).

When including the interaction between time to death and caregiving in model c, we see that caregiving sons have a positive development in earnings 5-4 years before a parent's death compared to non-caregiving sons. That said, caregiving sons have a more negative development in the years after the parent's death compared to noncaregiving sons. Model d shows that caregiving daughters deviate negatively from non-

\section{Employment}
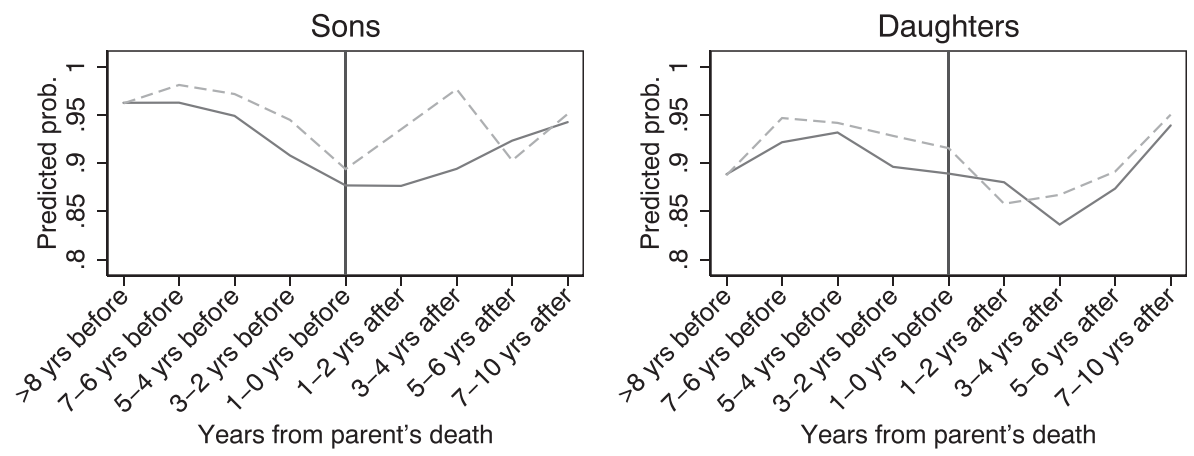

Non-caregivers

Caregivers

Fig. 3 Estimated impact of time (years) to loss of a lone parent on the probability of being in employment for caregivers and non-caregivers, estimated for sons and daughters separately 
Table 3 Results from linear regression model (OLS) of the impact of time (years) to a lone parent's death on log of standardised earnings conditional on employment, controlled for age, calendar year and individual fixed effects. Separate models by gender

\begin{tabular}{|c|c|c|c|c|c|c|c|c|}
\hline & \multicolumn{2}{|l|}{ a. Sons } & \multicolumn{2}{|c|}{ b. Daughters } & \multicolumn{2}{|l|}{ c. Sons } & \multicolumn{2}{|c|}{ d. Daughters } \\
\hline & Coef. & Std.Err & Coef. & Std.Err & Coef. & Std.Err & Coef. & Std.Err \\
\hline \multicolumn{9}{|c|}{ Time: 8 or more yrs. before (ref.) } \\
\hline 6-7 yrs. before & 0.031 & $(0.023)$ & $-0.066^{* *}$ & $(0.024)$ & 0.028 & $(0.025)$ & $-0.066^{*}$ & $(0.026)$ \\
\hline 5-4 yrs. before & 0.050 & $(0.031)$ & $-0.106^{* *}$ & $(0.032)$ & 0.033 & $(0.032)$ & $-0.097 * *$ & $(0.034)$ \\
\hline 3-2 yrs. before & 0.052 & $(0.040)$ & $-0.118 * *$ & $(0.040)$ & 0.044 & $(0.040)$ & $-0.092 *$ & $(0.042)$ \\
\hline $1-0$ yrs. before & 0.062 & $(0.048)$ & $-0.105^{*}$ & $(0.048)$ & 0.062 & $(0.048)$ & -0.079 & $(0.050)$ \\
\hline $1-2$ yrs. after & 0.034 & $(0.055)$ & $-0.166^{* *}$ & $(0.056)$ & 0.037 & $(0.056)$ & $-0.152 * *$ & $(0.057)$ \\
\hline $3-4$ yrs. after & 0.039 & $(0.063)$ & $-0.191 * *$ & $(0.064)$ & 0.054 & $(0.064)$ & $-0.173 * *$ & $(0.065)$ \\
\hline 5-6 yrs. after & 0.038 & $(0.071)$ & $-0.216^{* *}$ & $(0.072)$ & 0.060 & $(0.072)$ & $-0.230 * *$ & $(0.073)$ \\
\hline $7-10$ yrs. after & 0.072 & $(0.080)$ & $-0.228 * *$ & $(0.081)$ & 0.094 & $(0.080)$ & $-0.208 *$ & $(0.082)$ \\
\hline \multicolumn{9}{|c|}{ Interaction (Time*care): } \\
\hline 6-7 yrs. before*care & & & & & 0.014 & $(0.035)$ & -0.001 & $(0.031)$ \\
\hline 5-4 yrs. before*care & & & & & $0.075^{*}$ & $(0.035)$ & -0.026 & $(0.031)$ \\
\hline $3-2$ yrs. before* care & & & & & 0.025 & $(0.036)$ & $-0.073^{*}$ & $(0.031)$ \\
\hline $1-0$ yrs. before*care & & & & & -0.015 & $(0.038)$ & $-0.078^{*}$ & $(0.032)$ \\
\hline $1-2$ yrs. after*care & & & & & -0.021 & $(0.038)$ & -0.049 & $(0.033)$ \\
\hline $3-4$ yrs. after*care & & & & & $-0.072+$ & $(0.039)$ & $-0.066+$ & $(0.034)$ \\
\hline 5-6 yrs. after*are & & & & & $-0.091^{*}$ & $(0.041)$ & 0.022 & $(0.035)$ \\
\hline $7-10$ yrs. after*care & & & & & -0.065 & $(0.043)$ & $-0.077 *$ & $(0.036)$ \\
\hline Constant & $1.885^{* *}$ & $(0.463)$ & $1.334 * *$ & $(0.470)$ & $1.886^{* *}$ & $(0.463)$ & $1.332 * *$ & $(0.470)$ \\
\hline Person-years (n) & 6763 & & 6025 & & 6763 & & 6025 & \\
\hline Persons $(\mathrm{N})$ & 264 & & 245 & & 264 & & 245 & \\
\hline $\mathrm{R}^{2}$ (within): & 0.074 & & 0.078 & & 0.076 & & 0.081 & \\
\hline
\end{tabular}

$* * \mathrm{p}<0.01 * \mathrm{p}<0.05+\mathrm{p}<0.10$

caregiving daughters in how their earnings develop 3-0 years before a parent's death. There are also indications of an additional negative impact on earnings in the years after the loss of a parent, but here the overall trend in earnings is negative for all daughters who lose a parent, not only for those who reported being a caregiver.

Figure 4 shows estimates of the impact of time on standardised log earnings in the period, predicted after conducting the regression models $\mathrm{c}$ and $\mathrm{d}$ in Table 4. While Table 3 shows an overall stable trend in earnings for sons and a decreasing trend for daughters, the overall negative picture for daughters is not transmitted to Fig. 4. The explanation for this is found in the control for age and year dummies that are included in the regression models but not shown in Table $3 .^{7}$

\footnotetext{
7 The development in earnings is positively related to calendar year for daughters, but not significantly related to later calendar years for sons. Because of collinearity between time to death and calendar years, one must be careful with the interpretation of these coefficients. When the calendar year dummies are replaced with a continuous variable representing time, only the first eight coefficients change, while the interaction effects indicating how caregivers deviate from non-caregivers change only marginally.
} 


\section{Earnings}
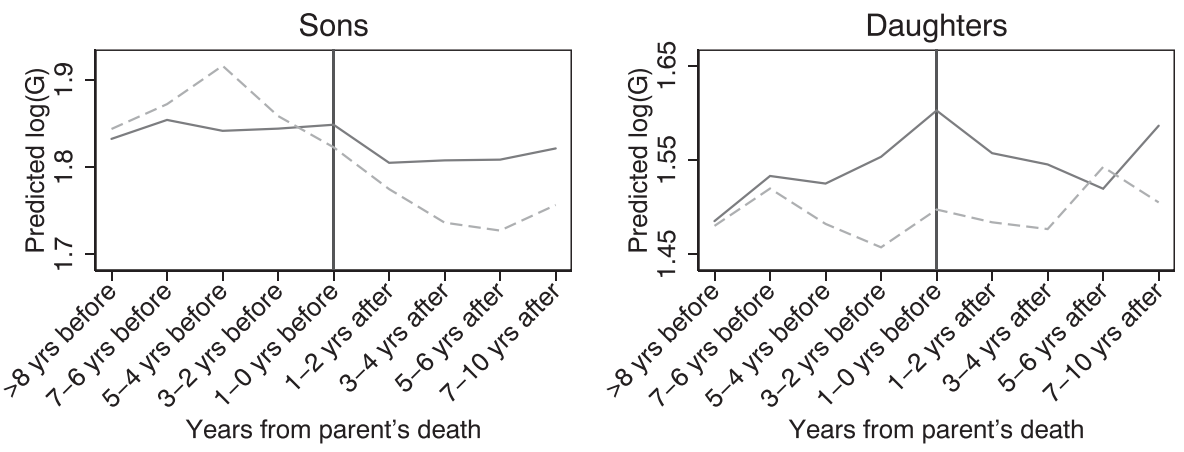

- Non caregivers ----- Caregivers

Fig. 4 Estimated impact of time (years) to loss of a lone parent on the log of earnings divided by $\mathrm{G}$ for caregivers and non-caregivers for sons and daughters separately

The focus of this article is the difference between caregivers and non-caregivers, and the results reported in both Table 3 and Fig. 4 indicate that the earnings of the two groups are developing differently in the period when they lose a lone parent. Caregiving daughters have a weaker development in their earnings in the years before and after the death compared to daughters who did not provide care, and caregiving sons experience a negative development in earnings after the loss of a parent.

\section{Robustness Assessment}

Previous research has argued that it is important for the assessment and interpretation of the consequences of caregiving that the measures of caregiving are sensitive to the intensity and character of the care provided. This section provides arguments for why the sample (and measurement of caregiving) chosen for the main analyses is preferred for answering the questions asked in the paper. The crucial point is balancing the need for an adequate sample size with a measure of caregiving that distinguishes the kind of care that is likely to come with a burden.

The measurement of caregiving is expected to be more robust for the group that lost a parent in the first years after the survey than for those who lost their parent later (up to ten years after the survey). To test this assumption, the analyses have been conducted for the total sample of respondents who lost their parents up to ten years after the survey (2007-2017) ${ }^{8}$ (see Tables 5 and 6 in Appendix). The analyses show the same tendencies regarding the difference between caregivers and non-caregivers as in the main analyses, but even though the sample is larger, the difference between the groups is not as significant as in the results shown above. This finding supports the assumption that caregiving measured closer to the time of death is more accurate, even though some observations are lost using this restriction.

The sample was also restricted to observations related to the loss of a lone parent. The reason for making this choice is that the burden of caregiving is expected to be higher

\footnotetext{
${ }^{8}$ In total 1793 respondents lost at least one of their parents in one of the ten years following the second wave of NorLAG (from 2007 to 2017).
} 
when the parent has no partner available. Additional analyses were conducted for a sample consisting of dyads that included both married and lone parents who died between 2007 and 2011 (Tables 7 and 8 in Appendix). When considering both lone and married parents, employment was no longer significantly lower around a parent's death - in fact, it was significantly higher for caregivers of both genders in the period around a parent's death compared to non-caregivers. This might indicate that the loss of a married parent is more often experienced in an earlier life phase - when employment is more stable - than the loss of a lone parent. The impact on earnings of losing a lone or married parent was showing the same tendency as in the main analyses. Although less negative and significant for daughters, the negative impact of time to the parent's death on sons' earnings was more significant than in the main analyses. This could be related to the larger sample size, but it could also indicate that a decrease in the earnings of sons around a parent's death is not necessarily as related to the caregiver burden as it is for daughters.

Although the survey questionnaire distinguishes between practical help and personal care given in 2007, the two measures are collapsed into one indicator in the analyses (as few respondents reported on only having provided personal care). Tables 9 and 10 in the Appendix provides additional analyses where only personal care is interacted with time to death. These analyses show no significant difference in employment between caregivers and non-caregivers, except for a positive effect for caregiving daughters 3 and more years after the parent's demise. The negative effect of time on earnings, found when practical help was included in the main model, was not repeated when using only personal care, with one exception: a negative impact for caregiving sons 5-10 years after the death of a parent.

The analyses of employment and earnings have also been conducted using random effects in addition to fixed effects, which gives similar results and coefficient estimates (available upon request). The binary employment outcome was also analysed in a conditional logit model yielding coefficients with the same tendency as the linear probability model, but with results that were less easy to interpret (See Table 4 in Appendix).

\section{Discussion}

The aim of the present study was to explore whether providing care to a parent in need of care had an impact on sons' and daughters' employment and earnings in Norway. The question was examined by focusing on changes in employment and earnings in the years before and after an adult child loses a lone parent. The data was collected in Norway, where female labour market participation is high and elder care is a public responsibility. Despite a de-familialised context, informal caregiving has been shown to be an important part of the welfare system, which depends on a sustainable balance between informal caregiving and labour market participation. This paper shows that this balance is fragile.

The data analysis addressing the probability of being employed showed a negative trend in both the years before and the period after the loss of a lone parent. There was, however, no negative effect of time to the parent's death on employment associated with being a caregiver compared to being a non-caregiver. Therefore, the negative effect observed in the total sample could not be ascribed to caregiving. Other explanations related to losing a parent, such as an effect of inheritance, grief or change in value orientation, cannot be excluded. Nevertheless, there was a difference between the caregivers and the non- 
caregivers in how their earnings were affected by having a parent entering the terminal stage of life. The analyses conducted separately for sons and daughters showed that caregiving daughters deviated significantly from non-caregiving daughters in their earnings before a parent's death. After a parent's death, caregivers of both genders had a more negative development in earnings than those who were not caregivers.

The results from this study are consistent with Fevang et al. (2012), who found a negative development in employment and earnings around the death of a parent. This paper adds to their results by showing that the drop in earnings is likely to be related to a caregiver role. However, the results did not support the assumption that the effect of time to a parent's death on employment was related to caregiving.

The results are in line with previous research that has shown that less intensive caregiving is more likely to affect work at the intensive margin, but not at the extensive margin. Since the most demanding tasks, such as personal care, are commonly taken care of by public services in the Norwegian context, adult children are less at risk of leaving employment to take care of their parents, but they may experience a negative effect on their earnings as a consequence of providing care in the terminal phase of their parents' lives.

Only daughters, not sons, who provided care experienced a penalty on their earnings before their parent's death - which is the period when actual caregiving takes place. Previous research has shown that the difference in consequences of caregiving between the genders can be attributed to the different care tasks that men and women take on when providing care. One explanation for the less significant impact that sons' caregiving has on their earnings before a parent's death could therefore be related to a difference in care intensity relating to not only the tasks but also the time used in caregiving. Intensity is important, and it is a limitation of the study that the number of hours of care provided is not measured.

Both sons and daughters experienced a negative impact of caregiving on earnings after a parent's death. One explanation is that adult children who provide care have less time to invest in career development and job advancement when their parents enter the terminal phase. Some might reduce work hours or take up paid or unpaid leave to cope with the situation; both might hamper their career development (Skira 2015). Earlier research has shown that caregiving daughters in Norway have a higher risk of absence from work due to sick leave (Ugreninov 2013; Løken et al. 2017; Abrahamsen and Grøtting 2019). Sick leave absence in Norway has a replacement rate of $100 \%$ of the wage from day one and therefore does not affect earnings immediately but has negative consequences on earnings in the longer run (Markussen 2012). A second explanation is that inheritance compensate for a drop in earnings. Previous studies show that the reception of a bequest or even its expectation can be a reason for reducing work hours or leaving the labour market (Brown et al. 2010; Bø et al. 2019). Also, Fevang et al. (2012) found a rise in labour supply among those who expected little or no inheritance in the years after the lone parent's death, while labour supply in the years before the parent's death was independent of the expected bequest. However, there is less reason to believe that caregivers in Norway differ much from non-caregivers in the receipt of inheritance. Legislation requires that children inherit from their parents and a large share of inheritance is shared equally between siblings. Thus, the possibility of rewarding one child for providing care above another is limited. In order to control for a "wealth shock" from inheritance, gross wealth each year was used as a control in Tables 11 and 12 available in the Appendix. It should be noted that information about gross wealth is not available for the years before 2002, and because of a large amount 
of missing data in the reference period before the parent's death, the variable is not included in the main analyses. When wealth is included in the model, the number of observations per respondent falls drastically. The coefficient size of the effect of caregiving is substantially the same but the results are no longer significant. A third explanation is that the terminal phase might lead to changes in sons' and daughters' view of life. Facing the death of a parent is an existential experience and may lead to changes in the choices that men and women make in their own lives (Umberson 2003). If this is the case, the results presented here suggest that caregiving sons and daughters are more liable to respond this way.

A limitation of this study is the small sample size. Although several thousand respondents were involved in the NorLAG study, only a small share experienced the loss of a lone parent during the five-year period after the survey. The supplementary analyses provided in the Appendix show that sample restrictions were necessary in order to conduct the analyses on an adequate sample but also that potentially important control variables had to be excluded because of missing information. Also, the inability to identify changes in caregiver status between the survey and the death year of the parent may be a source of lowered data quality. This might hide a true difference in employment between the two groups. Although the data in the NorLAG study is well designed to evaluate questions about intergenerational relationships, caregiving and work, the results prompt new questions, which need more detailed and comprehensive data to be answered.

In conclusion, the unique combination of register data and large-scale survey data in the NorLAG study has offered an opportunity to identify a lower bound of an effect on earnings measured in registers related to being a caregiver ahead of a parent's death measured in the survey. The negative impact of caregiving on earnings is particularly apparent for daughters who provide care to a parent in the terminal phase. The results indicate an economic penalty of caregiving to older parents that might exacerbate the already disadvantaged position of women entering the last years of their working lives with regard to wages and pension earnings. The gender division in both the provision of care to parents and the economic costs of caregiving might further contribute to economic inequalities between men and women.

Acknowledgements This study was conducted as a part of the AgePath project funded by the Research Council of Norway (grant no. 236997). The author would like to thank the AgePath team, seminar participants at Oslo Metropolitan University, Katharina Herlofson, Lena Magnusson, Viggo Nordvik, Kristin Aarland, Heidi Gautun, Espen Dahl, and two anonymous referees for their valuable comments and suggestions. Open Access funding provided by OsloMet - Oslo Metropolitan University.

Funding information The NorLAG data collections have been financed by The Research Council of Norway, four ministries, The Norwegian Directorate of Health, The Norwegian State Housing Bank, Statistics Norway and NOVA, OsloMet. NorLAG data are part of the ACCESS Life Course infrastructure funded by the National Financing Initiative for Research Infrastructure at the Research Council of Norway (Grant no. 195403 and no. 269920).

\section{Compliance with Ethical Standards}

Conflict of Interest The author declare no conflict of interest. 


\section{Appendix}

Table 4 Results from conditional logit regression model of the impact of time to a lone parent's death on employment, controlled for age, calendar year and individual fixed effects. Separate models by gender

\begin{tabular}{|c|c|c|c|c|c|c|c|c|}
\hline & \multicolumn{2}{|l|}{ a. Sons } & \multicolumn{2}{|c|}{ b. Daughters } & \multicolumn{2}{|l|}{ c. Sons } & \multicolumn{2}{|c|}{ d. Daughters } \\
\hline & Logit & $\mathrm{SE}$ & Logit & SE & Logit & SE & Logit & SE \\
\hline \multicolumn{9}{|c|}{8 or more yrs. before (ref.) } \\
\hline 6-7 yrs. before & -0.496 & $(0.524)$ & 0.073 & $(0.360)$ & -0.761 & $(0.557)$ & -0.193 & $(0.394)$ \\
\hline 5-4 yrs. before & -0.959 & $(0.736)$ & 0.015 & $(0.500)$ & $-1.402+$ & $(0.764)$ & -0.120 & $(0.534)$ \\
\hline $3-2$ yrs. before & $-2.139 *$ & $(0.904)$ & -0.674 & $(0.617)$ & $-2.564 * *$ & $(0.929)$ & -0.990 & $(0.640)$ \\
\hline $1-0$ yrs. before & $-2.961 * *$ & $(1.040)$ & $-1.350+$ & $(0.730)$ & $-3.381 * *$ & $(1.073)$ & $-1.629 *$ & $(0.753)$ \\
\hline $1-2$ yrs. after & $-2.777 *$ & $(1.182)$ & $-2.152 *$ & $(0.836)$ & $-3.327^{* *}$ & $(1.216)$ & $-2.238^{* *} *$ & $(0.857)$ \\
\hline 3-4 yrs. after & $-2.526+$ & $(1.328)$ & $-2.613 * *$ & $(0.935)$ & $-3.004^{*}$ & $(1.366)$ & $-2.861 * *$ & $(0.954)$ \\
\hline 5-6 yrs. after & $-2.994 *$ & $(1.480)$ & $-2.639 *$ & $(1.042)$ & $-2.927+$ & $(1.529)$ & $-2.748 * *$ & $(1.066)$ \\
\hline $7-10$ yrs. after & -2.777 & $(1.702)$ & $-2.406^{*}$ & $(1.189)$ & -2.625 & $(1.754)$ & $-2.367+$ & $(1.222)$ \\
\hline \multicolumn{9}{|c|}{ Interaction (Time*care): } \\
\hline 6-7 yrs. before*care & & & & & 1.128 & $(0.858)$ & 0.783 & $(0.514)$ \\
\hline 5-4 yrs. before* care & & & & & 1.444 & $(0.882)$ & 0.257 & $(0.501)$ \\
\hline 3-2 yrs. before*care & & & & & 0.938 & $(0.837)$ & 0.758 & $(0.480)$ \\
\hline $1-0$ yrs. before* ${ }^{*}$ care & & & & & 0.408 & $(0.662)$ & 0.538 & $(0.452)$ \\
\hline 1-2 yrs. after*care & & & & & 1.214 & $(0.795)$ & -0.072 & $(0.410)$ \\
\hline 3-4 yrs. after*care & & & & & 0.508 & $(0.808)$ & 0.410 & $(0.421)$ \\
\hline $5-6$ yrs. after*are & & & & & $-1.617 *$ & $(0.708)$ & -0.064 & $(0.520)$ \\
\hline 7-10 yrs. after*care & & & & & -1.255 & $(0.863)$ & -0.462 & $(0.687)$ \\
\hline Person-Years (n) & 2796 & & 3738 & & 2796 & & 3738 & \\
\hline Persons (N) & 104 & & 135 & & 104 & & 135 & \\
\hline
\end{tabular}

$* * p<0.01 * p<0.05+p<0.10$ 
Table 5 Results from a linear probability model of the impact of time to a lone parent's death (between 2007 and 2017) on employment controlled for age, calendar year and individual fixed effects. Separate models by gender

\begin{tabular}{|c|c|c|c|c|c|c|c|c|}
\hline & \multicolumn{2}{|l|}{ a. Sons } & \multicolumn{2}{|c|}{ b. Daughters } & \multicolumn{2}{|l|}{ c. Sons } & \multicolumn{2}{|c|}{ d. Daughters } \\
\hline & Coeff & SE & Coeff & SE & Coeff & SE & Coeff & SE \\
\hline \multicolumn{9}{|c|}{ Time: 8 or more yrs. before (ref.) } \\
\hline 6-7 yrs. before & 0.006 & $(0.009)$ & -0.004 & $(0.010)$ & 0.004 & $(0.009)$ & -0.011 & $(0.012)$ \\
\hline $5-4$ yrs. before & 0.015 & $(0.010)$ & -0.007 & $(0.012)$ & 0.007 & $(0.011)$ & -0.014 & $(0.014)$ \\
\hline 3-2 yrs. before & $0.029^{*}$ & $(0.012)$ & -0.013 & $(0.014)$ & $0.024+$ & $(0.013)$ & -0.023 & $(0.016)$ \\
\hline $1-0$ yrs. before & 0.021 & $(0.014)$ & -0.011 & $(0.017)$ & $0.026+$ & $(0.015)$ & -0.021 & $(0.018)$ \\
\hline $1-2$ yrs. after & $0.034 *$ & $(0.016)$ & -0.029 & $(0.019)$ & 0.026 & $(0.017)$ & -0.023 & $(0.020)$ \\
\hline 3-4 yrs. after & $0.072 * *$ & $(0.019)$ & $-0.051 *$ & $(0.022)$ & $0.059 * *$ & $(0.019)$ & $-0.039+$ & $(0.023)$ \\
\hline $5-6$ yrs. after & $0.076 * *$ & $(0.021)$ & $-0.044+$ & $(0.025)$ & $0.082 * *$ & $(0.022)$ & -0.041 & $(0.027)$ \\
\hline $7-10$ yrs. after & $0.079 * *$ & $(0.025)$ & -0.013 & $(0.029)$ & $0.081 * *$ & $(0.025)$ & -0.012 & $(0.030)$ \\
\hline \multicolumn{9}{|c|}{ Interaction (Time*care): } \\
\hline 6-7 yrs. before* care & & & & & 0.011 & $(0.016)$ & 0.020 & $(0.016)$ \\
\hline 5-4 yrs. before* care & & & & & $0.035^{*}$ & $(0.016)$ & 0.020 & $(0.016)$ \\
\hline $3-2$ yrs. before* ${ }^{*}$ care & & & & & 0.026 & $(0.016)$ & 0.027 & $(0.017)$ \\
\hline $1-0$ yrs. before* care & & & & & -0.019 & $(0.016)$ & 0.028 & $(0.017)$ \\
\hline $1-2$ yrs. after*care & & & & & $0.040 *$ & $(0.017)$ & -0.013 & $(0.018)$ \\
\hline $3-4$ yrs. after*care & & & & & $0.059 * *$ & $(0.020)$ & -0.033 & $(0.021)$ \\
\hline 5-6 yrs. after*care & & & & & -0.027 & $(0.025)$ & -0.008 & $(0.025)$ \\
\hline $7-10$ yrs. after*care & & & & & -0.002 & $(0.028)$ & 0.000 & $(0.028)$ \\
\hline Constant & $1.097 * *$ & $(0.217)$ & $0.876^{* *}$ & $(0.268)$ & $1.103 * *$ & $(0.217)$ & $0.876^{* *}$ & $(0.268)$ \\
\hline Person-Years (n) & 14,330 & & 13,766 & & 14,330 & & 13,766 & \\
\hline Persons $(\mathrm{N})$ & 575 & & 543 & & 575 & & 543 & \\
\hline R2 (within) & 0.119 & & 0.062 & & 0.121 & & 0.063 & \\
\hline
\end{tabular}

$* * p<0.01 * p<0.05+p<0.10$ 
Table 6 Results from an OLS regression model of the impact of time to a lone parent's death (between 2007 and 2017) on earnings conditional on employment and controlled for age, calendar year and individual fixed effects. Separate models by gender

\begin{tabular}{|c|c|c|c|c|c|c|c|c|}
\hline & \multicolumn{2}{|l|}{ a. Sons } & \multicolumn{2}{|c|}{ b. Daughters } & \multicolumn{2}{|l|}{ c. Sons } & \multicolumn{2}{|c|}{ d. Daughters } \\
\hline & Coeff & SE & Coeff & SE & Coeff & SE & Coeff & SE \\
\hline \multicolumn{9}{|c|}{ Time: 8 or more yrs. before (ref.) } \\
\hline 6-7 yrs. before & 0.014 & $(0.013)$ & $-0.025^{*}$ & $(0.013)$ & 0.012 & $(0.014)$ & -0.023 & $(0.015)$ \\
\hline 5-4 yrs. before & $0.040 * *$ & $(0.015)$ & $-0.054 * *$ & $(0.015)$ & $0.031^{*}$ & $(0.016)$ & $-0.052 * *$ & $(0.017)$ \\
\hline 3-2 yrs. before & $0.037 *$ & $(0.018)$ & $-0.060 * *$ & $(0.018)$ & $0.036+$ & $(0.019)$ & $-0.051 * *$ & $(0.019)$ \\
\hline $1-0$ yrs. before & 0.034 & $(0.021)$ & $-0.080^{* * *}$ & $(0.021)$ & 0.034 & $(0.022)$ & $-0.072 * *$ & $(0.022)$ \\
\hline $1-2$ yrs. after & 0.027 & $(0.024)$ & $-0.119 * *$ & $(0.024)$ & 0.025 & $(0.025)$ & $-0.121 * *$ & $(0.025)$ \\
\hline 3-4 yrs. after & 0.037 & $(0.028)$ & $-0.149 * *$ & $(0.027)$ & 0.042 & $(0.029)$ & $-0.148 * *$ & $(0.029)$ \\
\hline 5-6 yrs. after & 0.036 & $(0.032)$ & $-0.138 * *$ & $(0.031)$ & 0.053 & $(0.033)$ & $-0.151 * *$ & $(0.033)$ \\
\hline $7-10$ yrs. after & $0.065+$ & $(0.036)$ & $-0.125^{* *}$ & $(0.035)$ & $0.080 *$ & $(0.038)$ & $-0.107 * *$ & $(0.037)$ \\
\hline \multicolumn{9}{|c|}{ Interaction (Time*care): } \\
\hline 6-7 yrs. before* ${ }^{*}$ care & & & & & 0.009 & $(0.023)$ & -0.005 & $(0.020)$ \\
\hline 5-4 yrs. before*care & & & & & $0.039+$ & $(0.023)$ & -0.007 & $(0.020)$ \\
\hline $3-2$ yrs. before*care & & & & & 0.005 & $(0.024)$ & -0.026 & $(0.020)$ \\
\hline $1-0$ yrs. before*care & & & & & -0.002 & $(0.025)$ & -0.023 & $(0.021)$ \\
\hline $1-2$ yrs. after*care & & & & & 0.012 & $(0.026)$ & 0.004 & $(0.022)$ \\
\hline 3-4 yrs. after*care & & & & & -0.019 & $(0.029)$ & -0.006 & $(0.026)$ \\
\hline 5-6 yrs. after*care & & & & & $-0.081^{*}$ & $(0.037)$ & 0.035 & $(0.031)$ \\
\hline $7-10$ yrs. after*care & & & & & -0.060 & $(0.041)$ & $-0.056+$ & $(0.034)$ \\
\hline Constant & $1.710 * *$ & $(0.319)$ & $1.489 * *$ & $(0.323)$ & $1.714 * *$ & $(0.319)$ & $1.489 * *$ & $(0.323)$ \\
\hline Person-Years (n) & 13,296 & & 12,018 & & 13,296 & & 12,018 & \\
\hline Persons $(\mathrm{N})$ & 575 & & 537 & & 575 & & 537 & \\
\hline R2 (within) & 0.0602 & & 0.0696 & & 0.0610 & & 0.0702 & \\
\hline
\end{tabular}

$* * \mathrm{p}<0.01 * \mathrm{p}<0.05+\mathrm{p}<0.10$ 
Table 7 Results from a linear probability model of the impact of time to a lone or married parent's death on employment controlled for age, calendar year and individual fixed effects. Separate models by gender

\begin{tabular}{|c|c|c|c|c|c|c|c|c|}
\hline & \multicolumn{2}{|l|}{ a. Sons } & \multicolumn{2}{|c|}{ b. Daughters } & \multicolumn{2}{|l|}{ c. Sons } & \multicolumn{2}{|c|}{ d. Daughters } \\
\hline & Coeff & SE & Coeff & SE & Coeff & SE & Coeff & SE \\
\hline \multicolumn{9}{|c|}{ Time: 8 or more yrs. before (ref.) } \\
\hline 6-7 yrs. before & 0.009 & $(0.011)$ & -0.002 & $(0.014)$ & 0.000 & $(0.011)$ & -0.014 & $(0.015)$ \\
\hline 5-4 yrs. before & 0.018 & $(0.014)$ & -0.000 & $(0.019)$ & 0.009 & $(0.015)$ & -0.009 & $(0.020)$ \\
\hline $3-2$ yrs. before & 0.005 & $(0.018)$ & -0.006 & $(0.024)$ & -0.003 & $(0.018)$ & -0.015 & $(0.024)$ \\
\hline $1-0$ yrs. before & -0.015 & $(0.021)$ & -0.003 & $(0.028)$ & -0.024 & $(0.022)$ & -0.011 & $(0.029)$ \\
\hline $1-2$ yrs. after & -0.001 & $(0.025)$ & -0.001 & $(0.033)$ & -0.013 & $(0.025)$ & -0.001 & $(0.034)$ \\
\hline 3-4 yrs. after & 0.031 & $(0.028)$ & -0.012 & $(0.038)$ & 0.015 & $(0.028)$ & -0.013 & $(0.038)$ \\
\hline 5-6 yrs. after & 0.044 & $(0.031)$ & 0.010 & $(0.042)$ & 0.036 & $(0.032)$ & 0.010 & $(0.043)$ \\
\hline $7-10$ yrs. after & $0.061+$ & $(0.035)$ & 0.045 & $(0.048)$ & 0.054 & $(0.036)$ & 0.042 & $(0.048)$ \\
\hline \multicolumn{9}{|c|}{ Interaction (Time* care): } \\
\hline 6-7 yrs. before* care & & & & & $0.038^{*}$ & $(0.016)$ & $0.040^{*}$ & $(0.019)$ \\
\hline $5-4$ yrs. before $*$ care & & & & & $0.042 * *$ & $(0.016)$ & $0.031+$ & $(0.019)$ \\
\hline $3-2$ yrs. before*care & & & & & $0.033^{*}$ & $(0.016)$ & $0.039 *$ & $(0.019)$ \\
\hline $1-0$ yrs. before* ${ }^{*}$ care & & & & & $0.037 *$ & $(0.016)$ & $0.040 *$ & $(0.019)$ \\
\hline $1-2$ yrs. after*care & & & & & $0.047 * *$ & $(0.017)$ & 0.013 & $(0.020)$ \\
\hline 3-4 yrs. after*care & & & & & $0.066^{* *}$ & $(0.017)$ & 0.020 & $(0.020)$ \\
\hline 5-6 yrs. after*care & & & & & 0.023 & $(0.018)$ & 0.019 & $(0.021)$ \\
\hline $7-10$ yrs. after*care & & & & & 0.020 & $(0.019)$ & 0.032 & $(0.023)$ \\
\hline Constant & $0.933 * *$ & $(0.219)$ & $0.961 * *$ & $(0.290)$ & $0.936 * *$ & $(0.219)$ & $0.961 * *$ & $(0.290)$ \\
\hline Person-Years (n) & 13,659 & & 13,369 & & 13,659 & & 13,369 & \\
\hline Persons (N) & 497 & & 484 & & 497 & & 484 & \\
\hline R2 (within) & 0.122 & & 0.0769 & & 0.124 & & 0.0777 & \\
\hline
\end{tabular}

$* * \mathrm{p}<0.01 * \mathrm{p}<0.05+\mathrm{p}<0.10$ 
Table 8 Results from an OLS regression model of the impact of time to a lone or married parent's death on earnings conditional on employment, controlled for age, calendar year and individual fixed effects. Separate models by gender

\begin{tabular}{|c|c|c|c|c|c|c|c|c|}
\hline & \multicolumn{2}{|l|}{ a. Sons } & \multicolumn{2}{|c|}{ b. Daughters } & \multicolumn{2}{|l|}{ c. Sons } & \multicolumn{2}{|c|}{ d. Daughters } \\
\hline & Coeff & SE & Coeff & SE & Coeff & SE & Coeff & SE \\
\hline \multicolumn{9}{|c|}{ Time: 8 or more yrs. before (ref.) } \\
\hline 6-7 yrs. before & 0.003 & $(0.017)$ & $-0.041^{*}$ & $(0.017)$ & 0.005 & $(0.018)$ & $-0.040^{*}$ & $(0.018)$ \\
\hline $5-4$ yrs. before & 0.013 & $(0.022)$ & -0.034 & $(0.022)$ & 0.012 & $(0.023)$ & -0.026 & $(0.023)$ \\
\hline 3-2 yrs. before & 0.026 & $(0.028)$ & -0.026 & $(0.028)$ & 0.030 & $(0.029)$ & -0.016 & $(0.029)$ \\
\hline $1-0$ yrs. before & 0.010 & $(0.034)$ & 0.004 & $(0.034)$ & 0.020 & $(0.034)$ & 0.013 & $(0.035)$ \\
\hline $1-2$ yrs. after & -0.006 & $(0.039)$ & -0.026 & $(0.040)$ & 0.007 & $(0.040)$ & -0.026 & $(0.040)$ \\
\hline 3-4 yrs. after & 0.009 & $(0.045)$ & -0.045 & $(0.045)$ & 0.028 & $(0.045)$ & -0.031 & $(0.046)$ \\
\hline 5-6 yrs. after & 0.024 & $(0.050)$ & -0.055 & $(0.051)$ & 0.047 & $(0.051)$ & -0.063 & $(0.052)$ \\
\hline $7-10$ yrs. after & 0.042 & $(0.057)$ & -0.058 & $(0.057)$ & 0.055 & $(0.057)$ & -0.050 & $(0.058)$ \\
\hline \multicolumn{9}{|l|}{ Interaction (Time*care): } \\
\hline 6-7 yrs. before* care & & & & & -0.010 & $(0.026)$ & -0.004 & $(0.022)$ \\
\hline 5-4 yrs. before* care & & & & & -0.001 & $(0.026)$ & -0.027 & $(0.022)$ \\
\hline $3-2$ yrs. before* ${ }^{*}$ care & & & & & -0.023 & $(0.026)$ & $-0.037+$ & $(0.023)$ \\
\hline $1-0$ yrs. before* ${ }^{*}$ care & & & & & $-0.050+$ & $(0.027)$ & -0.033 & $(0.023)$ \\
\hline $1-2$ yrs. after*care & & & & & $-0.061^{*}$ & $(0.028)$ & -0.009 & $(0.024)$ \\
\hline 3-4 yrs. after*care & & & & & $-0.081 * *$ & $(0.028)$ & $-0.056^{*}$ & $(0.025)$ \\
\hline 5-6 yrs. after*care & & & & & $-0.090 * *$ & $(0.029)$ & 0.012 & $(0.026)$ \\
\hline $7-10$ yrs. after*care & & & & & -0.035 & $(0.030)$ & -0.040 & $(0.027)$ \\
\hline Constant & $1.939 * *$ & $(0.349)$ & $1.526^{* *}$ & $(0.341)$ & $1.941 * *$ & $(0.349)$ & $1.515 * *$ & $(0.341)$ \\
\hline Person-Years (n) & 12,791 & & 11,799 & & 12,791 & & 11,799 & \\
\hline Persons $(\mathrm{N})$ & 496 & & 480 & & 496 & & 480 & \\
\hline R2 (within) & 0.0926 & & 0.0920 & & 0.0941 & & 0.0928 & \\
\hline
\end{tabular}

$* * \mathrm{p}<0.01 * \mathrm{p}<0.05+\mathrm{p}<0.10$ 
Table 9 Results from a linear probability model of the impact of time to a lone parent's death on employment, controlled for age, calendar year and individual fixed effects. Separate models by gender. Time to death year is interacted with personal care

\begin{tabular}{|c|c|c|c|c|}
\hline & \multicolumn{2}{|l|}{ a. Sons } & \multicolumn{2}{|c|}{ b. Daughters } \\
\hline & Coeff & SE & Coeff & SE \\
\hline \multicolumn{5}{|c|}{ Time: 8 or more yrs. before (ref.) } \\
\hline 6-7 yrs. before & -0.012 & $(0.016)$ & 0.002 & $(0.021)$ \\
\hline $5-4$ yrs. before & -0.018 & $(0.021)$ & 0.004 & $(0.028)$ \\
\hline 3-2 yrs. before & -0.039 & $(0.027)$ & -0.028 & $(0.034)$ \\
\hline $1-0$ yrs. before & $-0.055+$ & $(0.032)$ & -0.059 & $(0.041)$ \\
\hline $1-2$ yrs. after & -0.025 & $(0.037)$ & $-0.094^{*}$ & $(0.047)$ \\
\hline 3-4 yrs. after & 0.020 & $(0.042)$ & $-0.128^{*}$ & $(0.054)$ \\
\hline $5-6$ yrs. after & 0.042 & $(0.047)$ & -0.089 & $(0.060)$ \\
\hline $7-10$ yrs. after & 0.070 & $(0.053)$ & -0.059 & $(0.068)$ \\
\hline \multicolumn{5}{|c|}{ Interaction (Time*care): } \\
\hline 6-7 yrs. before* care & 0.029 & $(0.036)$ & 0.031 & $(0.034)$ \\
\hline 5-4 yrs. before*care & 0.029 & $(0.036)$ & 0.012 & $(0.034)$ \\
\hline $3-2$ yrs. before*care & 0.056 & $(0.036)$ & 0.021 & $(0.034)$ \\
\hline $1-0$ yrs. before*care & -0.022 & $(0.036)$ & 0.012 & $(0.035)$ \\
\hline $1-2$ yrs. after*care & -0.012 & $(0.037)$ & 0.031 & $(0.036)$ \\
\hline $3-4$ yrs. after*care & -0.029 & $(0.038)$ & $0.090^{*}$ & $(0.036)$ \\
\hline 5-6 yrs. after*care & -0.064 & $(0.039)$ & $0.080^{*}$ & $(0.037)$ \\
\hline $7-10$ yrs. after*care & -0.060 & $(0.037)$ & $0.102 * *$ & $(0.037)$ \\
\hline Constant & $1.033^{* *}$ & $(0.302)$ & $0.800^{*}$ & $(0.395)$ \\
\hline Person-Years (n) & 6698 & & 6410 & \\
\hline Persons $(\mathrm{N})$ & 246 & & 231 & \\
\hline R2 (within) & 0.129 & & 0.068 & \\
\hline
\end{tabular}

$* * \mathrm{p}<0.01 * \mathrm{p}<0.05+\mathrm{p}<0.10$ 
Table 10 Results from an OLS regression model of the impact of time to a lone parent's death on earnings conditional on employment, controlled for age, calendar year and individual fixed effects. Separate models by gender. Time to death year is interacted with personal care

\begin{tabular}{|c|c|c|c|c|}
\hline & \multicolumn{2}{|l|}{ a. Sons } & \multicolumn{2}{|c|}{ b. Daughters } \\
\hline & Coeff & SE & Coeff & SE \\
\hline Time: 8 or more yrs. before (ref.) & . & (.) & . & (.) \\
\hline 6-7 yrs. before & 0.026 & $(0.025)$ & $-0.058 *$ & $(0.026)$ \\
\hline 5-4 yrs. before & 0.040 & $(0.033)$ & $-0.100 * *$ & $(0.034)$ \\
\hline 3-2 yrs. before & 0.051 & $(0.042)$ & $-0.098 *$ & $(0.043)$ \\
\hline $1-0$ yrs. before & 0.061 & $(0.050)$ & -0.071 & $(0.051)$ \\
\hline $1-2$ yrs. after & 0.033 & $(0.059)$ & $-0.120 *$ & $(0.059)$ \\
\hline 3-4 yrs. after & 0.048 & $(0.067)$ & $-0.140 *$ & $(0.068)$ \\
\hline 5-6 yrs. after & 0.066 & $(0.075)$ & $-0.167 *$ & $(0.076)$ \\
\hline $7-10$ yrs. after & 0.102 & $(0.084)$ & $-0.151+$ & $(0.085)$ \\
\hline \multicolumn{5}{|l|}{ Interaction (Time*care): } \\
\hline 6-7 yrs. before* care & 0.057 & $(0.055)$ & 0.021 & $(0.042)$ \\
\hline 5-4 yrs. before* care & 0.075 & $(0.055)$ & 0.025 & $(0.042)$ \\
\hline $3-2$ yrs. before* ${ }^{*}$ care & -0.027 & $(0.055)$ & -0.031 & $(0.043)$ \\
\hline $1-0$ yrs. before* care & 0.017 & $(0.059)$ & -0.008 & $(0.045)$ \\
\hline $1-2$ yrs. after*care & -0.027 & $(0.060)$ & 0.021 & $(0.046)$ \\
\hline $3-4$ yrs. after*care & -0.060 & $(0.062)$ & 0.062 & $(0.046)$ \\
\hline 5-6 yrs. after*care & $-0.145^{*}$ & $(0.064)$ & $0.090+$ & $(0.046)$ \\
\hline $7-10$ yrs. after*care & $-0.124^{*}$ & $(0.058)$ & -0.016 & $(0.046)$ \\
\hline Constant & $1.826^{* *}$ & $(0.474)$ & $1.341 * *$ & $(0.490)$ \\
\hline Person-Years (n) & 6273 & & 5625 & \\
\hline Persons $(\mathrm{N})$ & 246 & & 228 & \\
\hline R2 (within) & 0.074 & & 0.082 & \\
\hline
\end{tabular}

$* * \mathrm{p}<0.01 * \mathrm{p}<0.05+\mathrm{p}<0.10$ 
Table 11 Results from a linear probability model of the impact of time to a lone parent's death on employment, controlled for age, calendar year, individual fixed effects and wealth. Separate models by gender

\begin{tabular}{|c|c|c|c|c|}
\hline & \multicolumn{2}{|l|}{ a. Sons } & \multicolumn{2}{|c|}{ b. Daughters } \\
\hline & Coeff & $\mathrm{SE}$ & Coeff & SE \\
\hline \multicolumn{5}{|c|}{ Time: 8 or more yrs. before (ref.) } \\
\hline 6-7 yrs. before & -0.007 & $(0.025)$ & 0.015 & $(0.034)$ \\
\hline $5-4$ yrs. before & -0.007 & $(0.032)$ & 0.023 & $(0.041)$ \\
\hline 3-2 yrs. before & -0.036 & $(0.043)$ & -0.002 & $(0.052)$ \\
\hline $1-0$ yrs. before & -0.064 & $(0.054)$ & -0.014 & $(0.064)$ \\
\hline $1-2$ yrs. after & -0.054 & $(0.065)$ & -0.022 & $(0.076)$ \\
\hline 3-4 yrs. after & -0.021 & $(0.076)$ & -0.051 & $(0.089)$ \\
\hline $5-6$ yrs. after & 0.004 & $(0.086)$ & -0.012 & $(0.101)$ \\
\hline $7-10$ yrs. after & 0.018 & $(0.100)$ & 0.036 & $(0.116)$ \\
\hline \multicolumn{5}{|l|}{ Interaction (Time*care): } \\
\hline 6-7 yrs. before*care & -0.002 & $(0.048)$ & 0.035 & $(0.047)$ \\
\hline $5-4$ yrs. before*care & -0.004 & $(0.046)$ & 0.028 & $(0.045)$ \\
\hline 3-2 yrs. before*care & 0.022 & $(0.046)$ & 0.053 & $(0.045)$ \\
\hline $1-0$ yrs. before* ${ }^{*}$ care & 0.007 & $(0.046)$ & 0.049 & $(0.046)$ \\
\hline $1-2$ yrs. after*care & 0.046 & $(0.047)$ & 0.001 & $(0.046)$ \\
\hline $3-4$ yrs. after*care & 0.055 & $(0.047)$ & 0.038 & $(0.046)$ \\
\hline 5-6 yrs. after*care & -0.049 & $(0.048)$ & 0.019 & $(0.047)$ \\
\hline $7-10$ yrs. after*care & -0.026 & $(0.050)$ & 0.006 & $(0.049)$ \\
\hline Wealth & 0.000 & $(0.000)$ & -0.000 & $(0.000)$ \\
\hline Constant & $0.961 * *$ & $(0.058)$ & $0.914 * *$ & $(0.070)$ \\
\hline Person-Years (n) & 3869 & & 3646 & \\
\hline Persons (N) & 264 & & 248 & \\
\hline R2 (within) & 0.136 & & 0.0695 & \\
\hline
\end{tabular}

$* * \mathrm{p}<0.01 * \mathrm{p}<0.05+\mathrm{p}<0.10$ 
Table 12 Results from an OLS regression model of the impact of time to a lone parent's death on earnings conditional on employment, controlled for age, calendar year, individual fixed effects and wealth. Separate models by gender

\begin{tabular}{|c|c|c|c|c|}
\hline & \multicolumn{2}{|l|}{ a. Sons } & \multicolumn{2}{|c|}{ b. Daughters } \\
\hline & Coeff & SE & Coeff & SE \\
\hline \multicolumn{5}{|c|}{ Time: 8 or more yrs. before (ref.) } \\
\hline 6-7 yrs. before & $0.060+$ & $(0.033)$ & -0.002 & $(0.038)$ \\
\hline 5-4 yrs. before & $0.072+$ & $(0.044)$ & 0.011 & $(0.046)$ \\
\hline 3-2 yrs. before & 0.088 & $(0.058)$ & 0.050 & $(0.059)$ \\
\hline $1-0$ yrs. before & 0.111 & $(0.073)$ & 0.098 & $(0.073)$ \\
\hline $1-2$ yrs. after & 0.097 & $(0.088)$ & 0.060 & $(0.087)$ \\
\hline 3-4 yrs. after & 0.136 & $(0.103)$ & 0.065 & $(0.102)$ \\
\hline 5-6 yrs. after & 0.159 & $(0.118)$ & 0.038 & $(0.115)$ \\
\hline $7-10$ yrs. after & $0.230+$ & $(0.136)$ & 0.108 & $(0.132)$ \\
\hline \multicolumn{5}{|c|}{ Interaction (Time*care): } \\
\hline 6-7 yrs. before*care & -0.019 & $(0.063)$ & 0.010 & $(0.053)$ \\
\hline $5-4$ yrs. before* ${ }^{*}$ care & 0.043 & $(0.061)$ & -0.028 & $(0.051)$ \\
\hline $3-2$ yrs. before* ${ }^{*}$ care & 0.001 & $(0.061)$ & -0.067 & $(0.051)$ \\
\hline $1-0$ yrs. before ${ }^{*}$ care & -0.050 & $(0.062)$ & -0.077 & $(0.052)$ \\
\hline $1-2$ yrs. after*care & -0.050 & $(0.062)$ & -0.054 & $(0.053)$ \\
\hline 3-4 yrs. after*care & -0.100 & $(0.063)$ & -0.068 & $(0.053)$ \\
\hline 5-6 yrs. after*are & $-0.117+$ & $(0.064)$ & 0.006 & $(0.054)$ \\
\hline $7-10$ yrs. after*care & $-0.120+$ & $(0.067)$ & $-0.108+$ & $(0.056)$ \\
\hline Wealth & $0.000 * *$ & $(0.000)$ & $-0.000 *$ & $(0.000)$ \\
\hline Constant & $1.900 * *$ & $(0.087)$ & $1.501 * *$ & $(0.088)$ \\
\hline Person-Years (n) & 3552 & & 3201 & \\
\hline Persons (N) & 262 & & 242 & \\
\hline R2 (within) & 0.0970 & & 0.0767 & \\
\hline
\end{tabular}

$* * \mathrm{p}<0.01 * \mathrm{p}<0.05+\mathrm{p}<0.10$

Open Access This article is licensed under a Creative Commons Attribution 4.0 International License, which permits use, sharing, adaptation, distribution and reproduction in any medium or format, as long as you give appropriate credit to the original author(s) and the source, provide a link to the Creative Commons licence, and indicate if changes were made. The images or other third party material in this article are included in the article's Creative Commons licence, unless indicated otherwise in a credit line to the material. If material is not included in the article's Creative Commons licence and your intended use is not permitted by statutory regulation or exceeds the permitted use, you will need to obtain permission directly from the copyright holder. To view a copy of this licence, visit http://creativecommons.org/licenses/by/4.0/.

\section{References}

Abrahamsen, S. A., \& Grøtting, M. W. (2019). Formal Care of the Elderly and Health Outcomes among Adult Daughters. Working Papers in Economics. University of Bergen, Department of Economics.

Bauer, J., \& Sousa-Poza, A. (2015). Impacts of informal caregiving on caregiver: Employment, health and family. Journal of Population Ageing, 8, 113-145. https://doi.org/10.1007/s12062-015-9116-0. 
Biørn, E., Gaure, S., Markussen, S., \& Røed, K. (2013). The rise in absenteeism: Disentangling the impacts of cohort, age and time. Journal of Population Economics, 26(4), 1585-1608. https://doi.org/10.1007 /s00148-012-0403-2.

Birtha, M., \& Holm, K. (2017). Who cares? Study on the challenges and needs of family carers in Europe (pp. 1-68). Brussels: COFACE Families Europe.

Bø, E. E., Halvorsen, E., \& Thoresen, T. O. (2019). Heterogeneity of the Carnegie effect. Journal of Human resources 54(3), 726-759. doi:https://doi.org/10.3368/jhr.54.3.0915.7366R1.

Bolin, K., Lindgren, B., \& Lundborg, P. (2008). Your next of kin or your own career? Caring and working among the 50+ of Europe. Journal of Health Economics, 27(3), 718-738. https://doi.org/10.1016/j. jhealeco.2007.10.004.

Brandt, M. (2013). Intergenerational help and public assistance in Europe. European Societies, 15(1), 26-56. https://doi.org/10.1080/14616696.2012.726733.

Brandt, M., Haberkern, K., \& Szydlik, M. (2009). Intergenerational help and Care in Europe. European Sociological Review, 25(5), 585-601.

Brown, J. R., Coile, C. C., \& Weisbenner, S. J. (2010). The effect of inheritance receipt on retirement. The Review of Economics and Statistics, 92(2), 425-434. https://doi.org/10.1162/rest.2010.11182.

Carmichael, F., \& Charles, S. (2003). The opportunity costs of informal care: Does gender matter? Journal of Health Economics, 22(5), 781-803. https://doi.org/10.1016/S0167-6296(03)00044-4.

Carmichael, F., Charles, S., \& Hulme, C. (2010). Who will care? Employment participation and willingness to supply informal care. Journal of Health Economics, 29(1), 182-190. https://doi.org/10.1016/j. jhealeco.2009.11.003.

COFACE (2015). European reconciliation package. Confederation of Family Organisations in the European Union.

Colombo, F., Llena-Nozal, A., Mercier, J., \& Tjadens, F. (2011). Help wanted? Providing and paying for longterm care. OECD Health Policy Studies. Paris: OECD Publishing.

Crespo, L., \& Mira, P. (2014). Caregiving to elderly parents and employment status of European mature women. Review of Economics and Statistics, 96(4), 693-709.

Daatland, S. O., Veenstra, M., \& Lima, I. A. (2010). Norwegian sandwiches. On the prevalence and consequences of family and work role squeezes over the life course. European Journal of Ageing, 7(4), 271-281. https://doi.org/10.1007/s10433-010-0163-3.

Fevang, E., Kverndokk, S., \& Røed, K. (2012). Labor supply in the terminal stages of lone parents' lives. Journal of Population Economics, 25(4), 1399-1422. https://doi.org/10.1007/s00148-012-0402-3.

Finch, J., \& Mason, J. (1993). Negotiating family responsibilities. London: Tavistock/Routledge.

Foster, L., \& Walker, A. (2015). Active and successful aging: A European policy perspective. The Gerontologist, 55(1), 83-90. https://doi.org/10.1093/geront/gnu028.

Gabrielsen, B. (2013). Omsorgstjenester mot livets slutt. In J. Ramm (Ed.), Eldres bruk av helse-og omsorgstjenester. SSB Statistiske analyser: Oslo.

Gautun, H., \& Bratt, C. (2016). Caring too much? Lack of public services to older people reduces attendance at work among their children. European Journal of Ageing, 14, 1-12. https://doi.org/10.1007/s10433-016-0403-2.

Gautun, H., \& Hagen, K. (2010). How do middle-aged employees combine work with caring for elderly parents? Community, Work \& Family, 13(4), 393-409. https://doi.org/10.1080/13668800903360625.

Glenn, N. D. (2005). Quantitative applications in the social sciences: Cohort analysis. Thousand Oaks: SAGE Publications, Inc..

Grigoryeva, A. (2017). Own gender, sibling's gender, parent's gender. American Sociological Review, 82(1), 116-146. https://doi.org/10.1177/0003122416686521.

Heitmueller, A. (2007). The chicken or the egg?: Endogeneity in labour market participation of informal carers in England. Journal of Health Economics, 26(3), 536-559. https://doi.org/10.1016/j.jhealeco.2006.10.005.

Heitmueller, A., \& Inglis, K. (2007). The earnings of informal carers: Wage differentials and opportunity costs. Journal of Health Economics, 26(4), 821-841. https://doi.org/10.1016/j.jhealeco.2006.12.009.

Holmøy, E., Otnes, B., \& Haugstveit, F. V. (2016). Behovet for arbeidskraft og omsorgsboliger i pleieogomsorgssektoren mot 2060. SSB-rapport: Statistisk sentralbyrå.

Jacobs, J. C., Van Houtven, C. H., Laporte, A., \& Coyte, P. C. (2017). The impact of informal caregiving intensity on Women's retirement in the United States. Journal of Population Ageing, 10(2), 159-180. https://doi.org/10.1007/s12062-016-9154-2.

Jakobsson, N., Kotsadam, A., \& Szebehely, M. (2013). Informal eldercare and care for disabled children in the nordic countries: Prevalence and relation to employment. Nordic Journal Of Social Research, 4, 1-30.

Jolanki, O., Szebehely, M., \& Kauppinen, K. (2013). Family rediscovered? Working carers of older people in Finland and Sweden. In T. Kröger \& S. Yeandle (Eds.), Combining paid work and family care. Policies and experiences in international perspective (pp. 53-69). Bristol: Policy Press. 
Kotsadam, A. (2011). Does informal eldercare impede Women's employment? The case of European welfare states. Feminist Economics, 17(2), 121-144. https://doi.org/10.1080/13545701.2010.543384.

Kotsadam, A. (2012). The employment costs of caregiving in Norway. International Journal of Health Care Finance and Economics, 12(4), 269-283. https://oi.org/10.1007/s10754-012-9116-z.

Kridahl, L., \& Silverstein, M. (2019). Retirement and aging parents in the Swedish population. Journal of Population Ageing, 13, 81-112. https://doi.org/10.1007/s12062-019-09244-8.

Kröger, T., \& Yeandle, S. (2013). Combining paid work and family care. Bristol: Policy Press.

Leira, A. (1996). Parents, children and the state: Family obligations in Norway. Oslo: Institute for Social Research.

Leopold, T., Raab, M., \& Engelhardt, H. (2014). The transition to parent care: Costs, commitments, and caregiver selection among children. Journal of Marriage and Family, 76(2), 300-318. https://doi.org/10.1111/jomf.12099.

Lilly, M. B., Laporte, A., \& Coyte, P. C. (2007). Labor market work and home care's unpaid caregivers: A systematic review of labor force participation rates, predictors of labor market withdrawal, and hours of work. Milbank Quarterly, 85(4), 641-690. https://doi.org/10.1111/j.1468-0009.2007.00504.x.

Løken, K. V., Lundberg, S., \& Riise, J. (2017). Lifting the burden. Formal Care of the Elderly and Labor Supply of adult children. Journal of Human Resources, 52(1), 247-271. https://doi.org/10.3368/jhr.52.1.0614-6447R1.

Markussen, S. (2012). The individual cost of sick leave. Journal of Population Economics, 25(4), 1287-1306. https://doi.org/10.1007/s00148-011-0390-8.

Mason, K. O., Mason, W. M., Winsborough, H. H., \& Poole, W. K. (1973). Some methodological issues in cohort analysis of archival data. American Sociological Review(38), 242-258.

Ministry of Health and Care Services (2011). Innovation in the Care Services (NOU 2011:11).

Moussa, M. M. (2019). The relationship between elder care-giving and labour force participation in the context of policies addressing population ageing: A review of empirical studies published between 2006 and 2016. Ageing and Society, 39(6), 1281-1310. https://doi.org/10.1017/S0144686X18000053.

Romøren, T. I. (2003). Last years of long lives: The Larvik study. London: Routledge.

Saraceno, C., \& Keck, W. (2010). Can we identify intergenerational policy regimes in Europe? European Societies, 12(5), 675-696. https://doi.org/10.1080/14616696.2010.483006.

Schmitz, H., \& Westphal, M. (2017). Informal care and long-term labor market outcomes. Journal of Health Economics, 56, 1-18. https://doi.org/10.1016/j.jhealeco.2017.09.002.

Skira, M. M. (2015). Dynamic wage and employment effects of elder parent care. International Economic Review, 56(1), 63-93. https://doi.org/10.1111/iere.12095.

Spiess, C. K., \& Schneider, U. (2003). Interactions between care-giving and paid work hours among European midlife women, 1994 to 1996. Ageing \& Society, 23(01), 41-68. https://doi.org/10.1017/S0144686X02001010.

Strauss, S., \& Trommer, K. (2018). Productive ageing regimes in Europe: Welfare state typologies explaining elderly Europeans' participation in paid and unpaid work. Journal of Population Ageing, 11(4), 311-328. https://doi.org/10.1007/s12062-017-9184-4.

Torsteinsen, A., \& Holmøy, A. (2019). Den norske studien av livsløp, aldring og generasjon-tredje runde (NorLAG3). Dokumentasjonsrapport. Oslo: Statistics Norway.

Ugreninov, E. (2013). Offspring in squeeze: Health and sick leave absence among middle-aged informal caregivers. Journal of Population Ageing, 6(4), 323-338. https://doi.org/10.1007/s12062-013-9091-2.

Ulmanen, P., \& Szebehely, M. (2015). From the state to the family or to the market? Consequences of reduced residential eldercare in Sweden. International Journal of Social Welfare, 24(1), 81-92. https://doi.org/10.1111/ijsw.12108.

Umberson, D. (2003). Death of a parent: Transition to a new adult identity. Cambridge: Cambridge University Press.

Van Den Broek, T., Dykstra, P. A., \& Van Der Veen, R. J. (2019). Adult children stepping in? Long-term care reforms and trends in children's provision of household support to impaired parents in the Netherlands. Ageing and Society, 39(1), 112-137. https://doi.org/10.1017/S0144686X17000836.

Van Houtven, C. H., Coe, N. B., \& Skira, M. M. (2013). The effect of informal care on work and wages. Journal of Health Economics, 32(1), 240-252. https://doi.org/10.1016/j.jhealeco.2012.10.006.

Verbakel, E. (2017). How to understand informal caregiving patterns in Europe? The role of formal long-term care provisions and family care norms. Scandinavian Journal of Public Health, 46, 1-12. https://doi. org/10.1177/1403494817726197.

Williams, A. M., Wang, L., \& Kitchen, P. (2014). Differential impacts of care-giving across three caregiver groups in Canada: End-of-life care, long-term care and short-term care. Health and Social Care in the Community, 22(2), 187-196. https://doi.org/10.1111/hsc.12075.

Publisher's Note Springer Nature remains neutral with regard to jurisdictional claims in published maps and institutional affiliations. 